\title{
Association of decreased expression of long non- coding RNA LOC285194 with chemoradiotherapy resistance and poor prognosis in esophageal squamous cell carcinoma
}

Yu-suo Tong ${ }^{1 \dagger}$, Xi-lei Zhou ${ }^{3 \dagger}$, Xiao-wei Wang ${ }^{5}$, Qing-quan Wu ${ }^{4}$, Tong-xin Yang ${ }^{1}$, Jin Lv', Jin-song Yang ${ }^{2}$, Bin Zhu ${ }^{1 *}$ and Xiu-feng Cao ${ }^{1 *}$

\begin{abstract}
Background: Expression of the long non-coding RNA (InCRNA) LOC285194 was previously shown to be correlated with aggressive clinicopathological features and poor prognosis in several cancers. The aim of the present study was to explore the relationship between LOC285194 expression and clinical outcomes in esophageal squamous cell carcinoma (ESCC), so as to assess whether it could be a novel biomarker for prognosis and prediction of response to therapy on ESCC patients.

Methods: The method of quantitative real-time polymerase chain reaction (qRT-PCR) was used to measure LOC285194 expression in pretreatment biopsy specimens and matched normal tissue derived from ESCC patients who underwent preoperative chemoradiotherapy followed by surgical resection (CRT + S group; $n=55$ ) or from those who received surgical resection alone ( $\mathrm{S}$ group; $\mathrm{n}=87$ ). The association between LOC285194 expression and clinicopathological features and prognosis were then analyzed.

Results: LOC285194 expression was significantly down-regulated in ESCC tumor tissues when compared with the adjacent normal tissues $(p<0.001)$. Low expression of LOC285194 was associated with larger tumor size $(p=0.002)$, advanced TNM stage $(p=0.018)$, more lymph node metastases $(p=0.013)$ and distant metastases $(p=0.015)$. In the CRT + S group, the pathological complete response rate was 57\% (16/28) for the LOC285194-high group, and 15\% (4/27) for the LOC285194-low group. Univariate analysis revealed that low expression of LOC285194 was significantly correlated with CRT response $(p=0.002)$. Moreover, Kaplan-Meier survival analysis revealed that patients with low expression of LOC285194 had a decreased disease free survival (DFS) $(p<0.001)$ and overall survival (OS) $(p<0.001)$. Multivariable analysis further identified low expression of LOC285194 as an independent prognosis factor for CRT response $(p=0.011)$, DFS $(p<0.001)$ and OS $(p=0.002)$.

Conclusion: Decreased expression of LOC285194 could serve as a molecular marker to predict the clinical outcome of ESCC patients after surgery, and select patients who would benefit from preoperative CRT.
\end{abstract}

Keywords: Esophageal squamous cell carcinoma, Long non-coding RNA, LOC285194, Chemoradiotherapy, Prognosis

\footnotetext{
*Correspondence: zhubin@163.com; cxf551101@sina.com

${ }^{\dagger}$ Equal contributors

'Department of Surgical Oncology, Affiliated Nanjing Hospital of Nanjing Medical University and Oncology Center of Nanjing Medical University,

Nanjing, Jiangsu, China

Full list of author information is available at the end of the article
} 


\section{Introduction}

In Eastern Asia, 90\% of the esophageal cancers are esophageal squamous cell carcinoma (ESCC) [1]. When treated exclusively by surgery, the prognosis of patients with ESCC is poor, with 5-year survival rates ranging from $9 \%-40 \%$ [2]. Although preoperative chemoradiotherapy (CRT) is commonly recommended by many physicians to improve the rate of curative resection and prolong survival, the clinical outcomes from randomized trials are equivocal [3-5]. Indeed, patients with the same pathological types and the same clinical stages show significantly different survival benefits after the identical treatment. It has been previously reported that patients with pathological complete response (pathCR) have a better clinical outcome than those with less than pathCR [6]. Therefore, the identification of molecular markers related to tumor response to CRT could help to select patients who are most likely to benefit from the preoperative CRT.

Long non-coding RNAs (lncRNAs) represent a new class of non- protein-coding RNAs which are longer than 200 bases, and do not function as templates for protein synthesis [7]. Previous studies have proved that lncRNAs play a critical role in the development and progression of cancer [8]. Additionally, multiple studies have indicated that the expression levels of lncRNAs are dysregulated in different kinds of tumors, including ESCC [9], and the aberrant expression of lncRNAs are correlated with metastasis, recurrence and prognosis. Specifically, the lncRNA HOTAIR has been shown to play a role in breast cancer, MALAT1 has been related to lung cancer, and HULC is reported to contribute to liver cancer [10-12]. Recently, the relatively new field of IncRNA research has focused on their value in the diagnosis and treatment of cancer. Indeed, it has been suggested that lncRNAs may serve as molecular markers for diagnosis, prognosis and prediction of tumor response to treatment [13].

The lncRNA LOC285194 (Gene ID: 285194), also called LSAMP antisense RNA 3, consists of four exons with 2105 bases in length. It was first reported to be within a tumor suppressor unit in osteosarcoma and depletion of this lncRNA promoted proliferation of normal osteoblasts through regulation of apoptotic and cell cycle transcripts as well as VEGF receptor 1 [14]. Decreased of LOC285194 expression has been reported in several cancers, and was strongly associated with malignant potential and poor patient prognosis [14-16]. However, to date, the association between this lncRNA expression and the prognosis of patients with ESCC has not been elucidated. In this study we examined the expression level of LOC285194 in ESCC tumors tissues and adjacent normal tissues. The relationships between its expression and clinicopathological features were then analyzed so as to evaluate whether LOC285194 expression could be a useful biomarker for prognosis and prediction of response to therapy in ESCC patients.

\section{Materials and methods \\ Patients and samples}

One hundred and forty-two tumor tissues and paired adjacent normal samples were obtained from patients who, based on the biopsy specimens, were diagnosed with ESCC at Nanjing Hospital Affiliated to Nanjing Medical University $(\mathrm{n}=64)$ and Huai'an First Hospital Affiliated to Nanjing Medical University $(\mathrm{n}=78)$ between January 2009 and November 2010. All of the specimens were immediately frozen in liquid nitrogen and then stored at $-80^{\circ} \mathrm{C}$ until RNA extraction. Of the 142 patients with ESCC, 55 (39\%) patients underwent surgical treatment four or five weeks after completion of preoperative CRT (CRT + surgery [CRT $+\mathrm{S}]$ group). The remaining 87 (61\%) patients were administered with surgical resection alone (S group). All patients were selected in the study based on the following inclusion criteria: biopsy specimens were identified as ESCC by histopathological examination; no previous treatment had been received; no T4 or T1N0 tumors; and no evidences of distant organ metastasis. The clinical stage was determined according to the 7th edition of tumor-node-metastasis (TNM) classification for esophageal carcinoma (UICC, 2009). Written informed consent was obtained from all patients and the study was approved by the Ethics committee of Nanjing Hospital of Nanjing Medical University and Huaian First Hospital of Nanjing Medical University.

\section{Treatment}

$\mathrm{CRT}+\mathrm{S}$ group: Each patient underwent the same preoperative concurrent CRT which included a 5 -fluorouracil (5-FU) based regimen. Specifically, cisplatin $\left(20 \mathrm{mg} / \mathrm{m}^{2} /\right.$ day, for 5 days, IV) and 5 -FU $\left(500 \mathrm{mg} / \mathrm{m}^{2} /\right.$ day, for 5 days, $24 \mathrm{~h}$ continuous infusion) were administered on days 1-5. Standard premedications were used. Radiotherapy was performed on the first day of the first chemotherapy cycle. A total radiation dose of 40 Gy was given in 20 fractions of 2 Gy each, with 5 fractions per week for 4 weeks. Four or five weeks after completion of CRT, a standard thansthoracic en bloc esophagectomy with two-field lymph node dissection was performed.

$\mathrm{S}$ group: The surgical approach was the same as that described for the CRT $+\mathrm{S}$ group.

\section{Evaluation and follow-up}

The histopathological response to CRT was classified into four categories according to the following criteria: grade 1, no evidence of viable tumor cells; grade $2,<10 \%$ viable tumor cells; grade $3,11-50 \%$ viable tumor cells; grade $4,>50 \%$ viable tumor cells [17]. We then divided 
the four categories into two groups: the pathological complete response (pathCR) group, which consisted of grade 1 , and the < pathCR group, which consisted of grades $2-4$.

All patients were followed every 3 months during the first year, every 6 months for an additional 2 years, and then every year until March 2014.

\section{Cell lines and cell culture}

This study used five human ESCC cell lines (KYSE30, KYSE 70, KYSE 150, KYSE510 and Eca109) and one normal human esophageal epithelial cell (Het-1A). All the cells were generous gifts from Dr. Zhi-hua Liu at the State Key Laboratory of Molecular Oncology, Cancer Institute, Chinese Academy of Medical Sciences (Beijing, China) [9]. These cells were grown in RPMI-1640 (Invitrogen, Carlsbad, CA) medium supplemented with $10 \%$ fetal bovine serum (Gibco, Grand Island, NY) and $1 \%$ penicillin-streptomycin at $37^{\circ} \mathrm{C}$ with $5 \% \mathrm{CO}_{2}$.

\section{RNA isolation and CDNA synthesis}

Total RNAs were extracted from tumor tissues and adjacent normal tissues using Trizol reagent (Invitrogen, Carlsbad, CA, USA) according to the manufacturer's instructions. The yield and quality of total RNA was evaluated by measuring the absorbance at 260 and $280 \mathrm{~nm}$. Only samples with an $\mathrm{A}_{260}: \mathrm{A}_{280}$ ratio between 1.8 and 2.1 was considered for further analysis. cDNAs were synthesized using the PrimeScript ${ }^{\text {tw }}$ RT reagent kit with gDNA Eraser (Takara, Dalian, China) according to the manufacturer's protocol. Briefly, $1 \mu \mathrm{g}$ total RNA, $2 \mu \mathrm{l} 5 \times$ gDNA Eraser Buffer, $1 \mu \mathrm{l}$ gDNA Eraser and RNase Free $\mathrm{dH}_{2} \mathrm{O}$, were combined in a total reaction volume of $10 \mu \mathrm{l}$ and incubated at $42^{\circ} \mathrm{C}$ for $2 \mathrm{~min}$ to eliminate the genomic DNA. Ten microliters of reverse-transcription reaction mixture (consisted of $4 \mu \mathrm{l} 5 \times$ PrimeScript Buffer 2, $1 \mu \mathrm{l}$ PrimeScript RT Enzyme Mix 1, $1 \mu \mathrm{l}$ RT Primer Mix, and $4 \mu \mathrm{l}$ RNase Free $\mathrm{dH}_{2} \mathrm{O}$ ) was then added, and the mixture was incubated at $37^{\circ} \mathrm{C}$ for $15 \mathrm{~min}$, followed by $85^{\circ} \mathrm{C}$ for $5 \mathrm{~s}$ to generate the cDNA.

\section{Quantitative real-time PCR (qRT-PCR)}

The expression of LOC285194 was quantified using SYBR $^{\circ}$ Premix Ex Tag ${ }^{\text {ma }}$ II (Takara, Dalian, China) according to the manufacturer's instructions on the ABI 7500 Real-Time PCR System (Applied Biosystems, Foster City, CA). Briefly, the $20 \mu \mathrm{l}$ reaction mixtures were incubated at $95^{\circ} \mathrm{C}$ for $30 \mathrm{~s}$ for the initial denaturation stage, followed by 40 cycles at $95^{\circ} \mathrm{C}$ for $5 \mathrm{~s}$ and $60^{\circ} \mathrm{C}$ for $34 \mathrm{~s}$. GAPDH was used to normalize the target gene expression. The $\Delta \mathrm{Ct}$ method was used to calculate the relative expression of LOC285194 in ESCC tumor tissues or ESCC cell lines in comparison with paired normal tissues or cells, respectively. Each sample was examined in triplicate.
The primers used in this study were synthesized by Invitrogen with the sequences as follows: 5'- TGTG CCTGTTTGACCTCTGA-3'(sense) and 5'-AGGAAG GATAAA AGACCGACCA -3'(antisense) for LOC285 194; 5'-TGCACCACCAACTGCTTAGC-3'(sense) and 5'-GGCATGGACTGTGGTCATGAG -3' (antisense) for GAPDH.

\section{Statistical analysis}

All statistical analyses were performed using the Statistical Program for Social Sciences (SPSS) 20.0 software. Overall survival (OS) was defined as the time from registration to death or until last follow-up date. Disease free survival (DFS) was calculated from registration to detection of tumor recurrence or until last follow-up date. The correlation between LOC285194 expression and clinicopathological characteristics were evaluated by the $X^{2}$ test. DFS and OS were calculated by Kaplan-Meier survival analysis and compared by the log rank test. To assess the factors that influenced the CRT response, multiple logistic regression analysis was performed on the factors that were shown to be significant on univariate analysis. All statistical analysis were two sided and $p$ values less than 0.05 were considered significant.

\section{Results}

\section{Patient characteristics}

Patient clinicopathological characteristics were shown in Table 1 . The cohort comprised 48 females and 94 males, with an average age of 64.5 years (range, 41 to 75 ). In the $\mathrm{S}$ group, clinical stages of the 87 patients were as follows: 13 cases, stage IIA; 21 cases, stage IIB; and 53 cases, stage III.

In the CRT $+\mathrm{S}$ group, all 55 patients underwent the same preoperative concurrent CRT regimen. Twenty patients achieved pathCR, and the less than pathCR was observed in the remaining 35 patients.

Of the 142 patients with ESCC, the median follow-up time was 23 months (range, 3 - 36 months), with 97 (68\%) tumor recurrence and $89(63 \%)$ cancer-related death.

\section{Expression of LOC285194 in ESCC}

To assess whether LOC285194 expression was associated with clinicopathologic characteristics in ESCC, we first measured its expression level by qRT-PCR in 142 paired tumor samples and adjacent non-tumor tissues. We detected that LOC285194 expression was significantly down-regulated in tumor tissues when compared to the adjacent normal tissues $(p<0.001$; Figure 1A). Approximately $69 \%(98 / 142)$ of the tumor samples had $>2$-folds lower LOC285194 expression than that in non-tumor tissues. Furthermore, we also examined the level of LOC285194 in five ESCC cell lines and one 
Table 1 Correlation between LOC285194 expression and clinicopathologic characteristics of 142 ESCC patients

\begin{tabular}{|c|c|c|c|}
\hline \multirow[t]{2}{*}{ Variables } & \multicolumn{2}{|c|}{ LncRNA LOC285194 subgroup $^{a}$} & \multirow[t]{2}{*}{$P^{\mathrm{b}}$ valu } \\
\hline & Low & High & \\
\hline All cases & 71 & 71 & \\
\hline \multicolumn{4}{|l|}{ Gender } \\
\hline Male & $49(69.1 \%)$ & $45(63.3 \%)$ & 0.478 \\
\hline Female & $22(30.0 \%)$ & $26(36.7 \%)$ & \\
\hline Age (years) & & & 0.614 \\
\hline$\leq 55$ & $8(11.3 \%)$ & $10(14.1 \%)$ & \\
\hline$>55$ & $63(88.7 \%)$ & $61(85.9 \%)$ & \\
\hline Tumor size $(\mathrm{cm})$ & & & $0.002^{*}$ \\
\hline$\leq 5$ & $39(55.0 \%)$ & $57(80.3 \%)$ & \\
\hline$>5$ & $32(45.0 \%)$ & $14(19.7 \%)$ & \\
\hline Tumor location & & & 0.573 \\
\hline Cervical/upper thoracic & $6(8.5 \%)$ & $8(11.3 \%)$ & \\
\hline Middle/lower thoracic & $65(91.5 \%)$ & $63(88.7)$ & \\
\hline Histologic grade & & & $0.022^{*}$ \\
\hline G1 & $6(8.5 \%)$ & $7(9.9 \%)$ & \\
\hline G2 & $36(50.7 \%)$ & $50(70.4 \%)$ & \\
\hline $\mathrm{G} 3 / \mathrm{G} 4$ & $29(40.8 \%)$ & $14(19.7 \%)$ & \\
\hline Smoking status & & & 0.603 \\
\hline Ever/current & $28(39.4 \%)$ & $25(35.2 \%)$ & \\
\hline Never & $43(60.6 \%)$ & $46(64.8 \%)$ & \\
\hline Alcohol consumption & & & 0.206 \\
\hline Ever/current & 17 (23.9\%) & $11(15.5 \%)$ & \\
\hline Never & $54(76.1 \%)$ & $60(84.5 \%)$ & \\
\hline T status & & & 0.27 \\
\hline $\mathrm{T} 1 / 2$ & $18(25.4 \%)$ & $24(33.8 \%)$ & \\
\hline $\mathrm{T} 3 / 4$ & $53(74.6 \%)$ & 47 (66.2\%) & \\
\hline $\mathrm{N}$ status & & & $0.013^{*}$ \\
\hline NOMO & $23(32.4 \%)$ & 39 (54.9\%) & \\
\hline N1M0 & $22(31.0 \%)$ & 19 (26.8\%) & \\
\hline M1-lym ${ }^{c}$ & $26(36.6 \%)$ & $13(18.3 \%)$ & \\
\hline M status & & & $0.015^{*}$ \\
\hline Mo & $45(63.4 \%)$ & 58 (81.7\%) & \\
\hline M1-lym & $26(36.6 \%)$ & $13(18.3 \%)$ & \\
\hline Clinical stage & & & $0.018^{*}$ \\
\hline landl| & $26(36.6 \%)$ & $40(56.3 \%)$ & \\
\hline III & $45(63.4 \%)$ & 31 (43.7\%) & \\
\hline CRT response & 27 & 28 & $0.001^{*}$ \\
\hline PathCR ${ }^{d}$ & $4(29.6 \%)$ & $16(67.9 \%)$ & \\
\hline Less than PathCR & $23(70.4 \%)$ & $12(32.1 \%)$ & \\
\hline
\end{tabular}

a Median expression level was used as a cutoff to divide the 142 patients into LOC285194 low group $(n=71)$ and LOC285194 high group $(n=71)$. ${ }^{b}$ Chi-square test. ${ }^{\mathrm{C}} \mathrm{M} 1-\mathrm{lym}$, distant lymph node metastasis. ${ }^{\mathrm{d}} \mathrm{PathCR}$, pathologic complete response. ${ }^{*} p<0.05$. normal esophageal epithelial cell. Among the 5 tumor cell lines, the LOC285194 level was lower in 3(KYSE30, KYSE510, Eca109) as compared with the normal esophageal epithelial cell $(p<0.05$; Figure 1B), but no statistical differences were observed for KYSE70 and KYSE150.

\section{LOC285194 expression and clinicopathological characteristics}

To further analyze whether there was an association between LOC285194 expression and specific clinicopathological parameters in patients with ESCC, we then used the median expression level of LOC285194 as a cutoff to divide the 142 patients into LOC285194-high ( $\mathrm{n}=71$, with an average $\Delta$ Ct expression value of 8.29) and low groups ( $\mathrm{n}=71$, with an average $\Delta \mathrm{Ct}$ expression value of 11.96). We found that the LOC285194-low group was significantly associated with larger tumor size, worse histologic grade, advanced TNM stage, and more lymph node metastasis and distant metastases $(\mathrm{p}<0.05$; Table 1$)$. However, statistical association between LOC285194 expression and other clinicopathological data including gender, age, tumor location, smoking status, alcohol consumption and depth of invasion released no significant differences $(p>0.05$; Table 1$)$.

\section{Correlation between LOC285194 expression and pathological response to CRT}

We next sought to explore whether LOC285194 expression could be a predictable molecular marker for CRT response on ESCC patients. We first investigated the association between LOC285194 expression level and pathological response to CRT in the CRT $+\mathrm{S}$ group. Of the 55 patients, the pathCR rate was $57 \%(16 / 28)$ in the LOC285194- high group, while it was only $15 \%(4 / 27)$ in the LOC285194-low group. The LOC285194-low group had a significantly lower response to CRT than that of LOC285194-high $\operatorname{group}(p=0.001)$. In other words, patients with low expression of LOC285194 showed resistance to CRT. These data suggested that LOC285194 could be a useful molecular maker for predicting the sensitivity to CRT on ESCC patients. Consequently, univariate analysis was then performed to determine whether LOC285194 was a feasible molecular maker for prediction of response to CRT, the results revealed that only LOC285194 expression was associated with tumor response to CRT (OR, 0.130; 95\% CI, 0.036-0.478; $p=0.002$; Table 2). Unexpectedly, no other clinical factors were observed to be associated with CRT response. However, age, gender, tumor size, tumor location, lymphatic metastases, distant metastases and clinical stage trended toward a correlation with CRT response and were included in further multiple logistic regression analysis along with LOC285194. Multivariate analysis indicated that low expression of LOC285194 was the only independent risk 


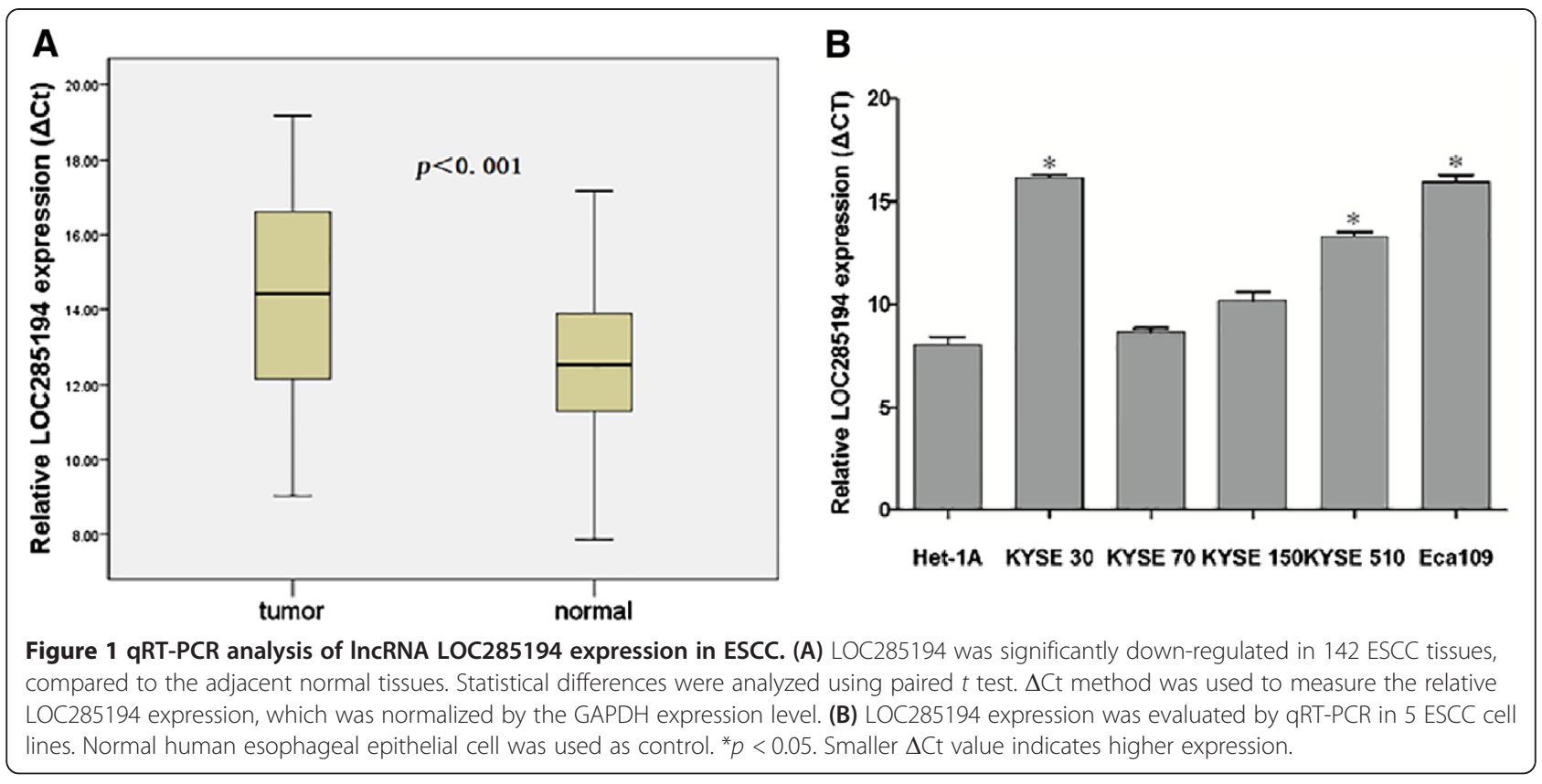

factor for CRT response (OR, 0.133; 95\% CI, 0.028-0.624; $p=0.011$, Table 2).

\section{Association between LOC285194 expression and prognosis after esophagectomy}

Kaplan-Meier survival analysis was used to investigate the association between the LOC285194 expression and the prognosis of patients with ESCC after esophagectomy. From the Kaplan-Meier survival curves, we found that patients with low expression of LOC285194 had poorer DFS $(p<0.001$; Figure 2A) and OS $(p<0.001$; Figure 2B) as compared with the LOC285194-high group. Moreover, multivariate analysis revealed that low expression of LOC285194 (HR, 0.341; 95\% CI, 0.193$0.602 ; p<0.001$ and HR, 0.388; 95\% CI, 0.210-0.715; $p=0.002$ for DFS and OS, respectively) as well as distant metastasis (HR, 2.123; 95\% CI, 1.063-4.240; $p=0.033$ and HR, 2.389; 95\% CI, 1.132-5.041; $p=0.022$ for DFS and OS, respectively) were independent prognosis factors that affected the DFS and OS of ESCC patients after esophagectomy (Table 3).

\section{Discussion}

Esophageal squamous cell carcinoma (ESCC) is one of the most virulent malignancies worldwide with the 5-year survival rate less than 30\% [18]. Although there have been recent improvements in combination treatments including chemoradiotherapy(CRT) alone or as an adjunct prior to surgery, local recurrences and distant metastases are still common, and the median survival time for ESCC patients continues to be poor. The dismal outcomes of ESCC are largely due to our inability to select the optimum therapy and CRT resistance [3]. Therefore, the exploration of novel molecular markers is very important to help select patients who will benefit from CRT as well as identify therapeutic targets.

LncRNAs are a new class of transcripts recently discovered to be pervasively transcribed in human genome and play a critical role in epigenetic regulation [19]. In addition, as with microRNA, IncRNAs may function as tumor markers for the prediction of tumor prognosis $[13,20]$. Here we reported IncRNA LOC285194, which was previously shown to function as a tumor suppressor in osteosarcoma and was significantly down-regulated in 43 osteosarcoma tumor samples and 5 osteosarcoma cell lines [14]. In addition, expression of LOC285194 deletion in tumor was found to be associated with poor prognosis of osteosarcoma patients. The misexpression of this lncRNA was also discovered in colorectal cancer, and patients with low expression of LOC285194 had a shorter DFS [16]. This common characteristic thus strengthened the clinical application value of LOC285194. Therefore, we hypothesized that LOC285194 expression was also decreased in ESCC tumor tissues and decreased of this IncRNA may influence the treatment outcomes and could predict the prognosis of ESCC patients.

To test this hypothesis, tissue samples from $142 \mathrm{pa}$ tients with ESCC were selected. The qRT-PCR showed that LOC285194 was significantly down-regulated in ESCC tumor tissues compared to the adjacent nontumor tissues. Furthermore, this significantly lower expression was also discovered in 3 ESCC cell lines when compared with that in normal esophageal epithelial cell. We then used the median expression level of LOC285194 as a 
Table 2 Univariate and multivariate logistic regression analysis of factors associated with pathologic response

\begin{tabular}{|c|c|c|c|c|c|c|c|c|c|}
\hline \multirow[b]{2}{*}{ Variables } & \multirow[b]{2}{*}{ Case } & \multirow[b]{2}{*}{ PathCR } & \multirow[b]{2}{*}{$<$ pathCR } & \multicolumn{3}{|c|}{ Univariate analysis } & \multicolumn{3}{|c|}{ Multivariate analysis } \\
\hline & & & & $\overline{\mathrm{OR}}$ & $95 \% \mathrm{Cl}$ & $p$ value & OR & $95 \% \mathrm{Cl}$ & $p$ value \\
\hline \multicolumn{10}{|l|}{ Ages } \\
\hline$\leq 55$ & 12 & 2 & 10 & 0.278 & $0.054-1.424$ & 0.125 & 0.302 & $0.049-1.874$ & 0.199 \\
\hline$>55$ & 43 & 18 & 25 & & & & & & \\
\hline \multicolumn{10}{|l|}{ Gender } \\
\hline Male & 34 & 9 & 25 & 0.372 & $0.104-1.030$ & 0.056 & 0.415 & $0.103-1.676$ & 0.217 \\
\hline Female & 21 & 11 & 10 & & & & & & \\
\hline \multicolumn{10}{|l|}{ Tumor size $(\mathrm{cm})$} \\
\hline$\leq 5$ & 35 & 14 & 21 & 1.556 & $0.482-5.019$ & 0.460 & 0.617 & $0.131-2.905$ & 0.541 \\
\hline$>5$ & 20 & 6 & 14 & & & & & & \\
\hline \multicolumn{10}{|l|}{ Tumor location } \\
\hline Cervical/upper thoracic & 14 & 7 & 7 & 2.154 & $0.625-7.421$ & 0.224 & 1.757 & $0.372-8.298$ & 0.477 \\
\hline Middle/lower thoracic & 41 & 13 & 28 & & & & & & \\
\hline \multicolumn{10}{|l|}{ Histologic grade } \\
\hline G1 & 8 & 3 & 5 & 0.873 & $0.172-4.429$ & 0.870 & nd & nd & nd \\
\hline G2 & 27 & 11 & 16 & 1.400 & $0.250-7.830$ & 0.702 & nd & nd & nd \\
\hline G3 & 20 & 6 & 14 & & & & & & \\
\hline \multicolumn{10}{|l|}{ T status } \\
\hline $\mathrm{T} 1 / 2$ & 14 & 6 & 8 & 1.446 & $0.419-4.997$ & 0.560 & nd & nd & nd \\
\hline T3 & 41 & 14 & 27 & & & & & & \\
\hline \multicolumn{10}{|l|}{$\mathrm{N}$ status } \\
\hline Negative & 20 & 10 & 10 & 2.500 & $0.797-7.839$ & 0.116 & 0.508 & $0.027-9.577$ & 0.651 \\
\hline Positive & 35 & 10 & 25 & & & & & & \\
\hline \multicolumn{10}{|l|}{ M status } \\
\hline Mo & 39 & 16 & 23 & 2.087 & $0.586-7.651$ & 0.267 & 1.250 & $0.212-7.368$ & 0.805 \\
\hline M1-lym & 16 & 4 & 12 & & & & & & \\
\hline \multicolumn{10}{|l|}{ Clinical stage } \\
\hline landll & 21 & 10 & 11 & 2.182 & $0.705-6.756$ & 0.176 & 2.102 & $0.109-40.483$ & 0.623 \\
\hline III & 34 & 10 & 24 & & & & & & \\
\hline \multicolumn{10}{|l|}{ LOC285194 } \\
\hline low & 27 & 4 & 23 & 0.130 & $0.036-0.478$ & $0.002^{*}$ & 0.133 & $0.028-0.624$ & $0.011^{*}$ \\
\hline high & 28 & 16 & 12 & & & & & & \\
\hline
\end{tabular}

cutoff to divide the 142 patients into the LOC285194low group and the LOC285194-high group to further investigate the association between LOC285194 expression and clinicopathological characteristics. Patients with low expression of LOC285194 showed larger tumor size, worse histologic grade, advanced TNM stage, more lymph node metastasis and distant metastases than the LOC285194-high group. Namely, the low expression level of LOC285194 was associated with malignant potential and aggressive clinicopathological features in ESCC. However, the exact mechanisms behind the dysregulation of LOC285194 expression in ESCC remain unclear. In the study by Liu Q et al, LOC285194 was found to be specifically induced by wild-type p53, p53 directly interacted with the $\mathrm{p} 53$ response element in the upstream of LOC285194 to induce its transcription [15]. Decreased expression of LOC285194 could be explained by p53 status, because p53 mutation or deletion could account for more than $50 \%$ of ESCC cases[21-23].

In patients with ESCC, preoperative CRT is often performed as an adjuvant treatment to improve survival [24]. However, only $13-49 \%$ patients who have pathCR will benefit from the treatment, the remaining 50\% patients present the CRT resistance[25]. To our knowledge to date, no studies have been performed regarding the association between lncRNA expression and the pathologic response 


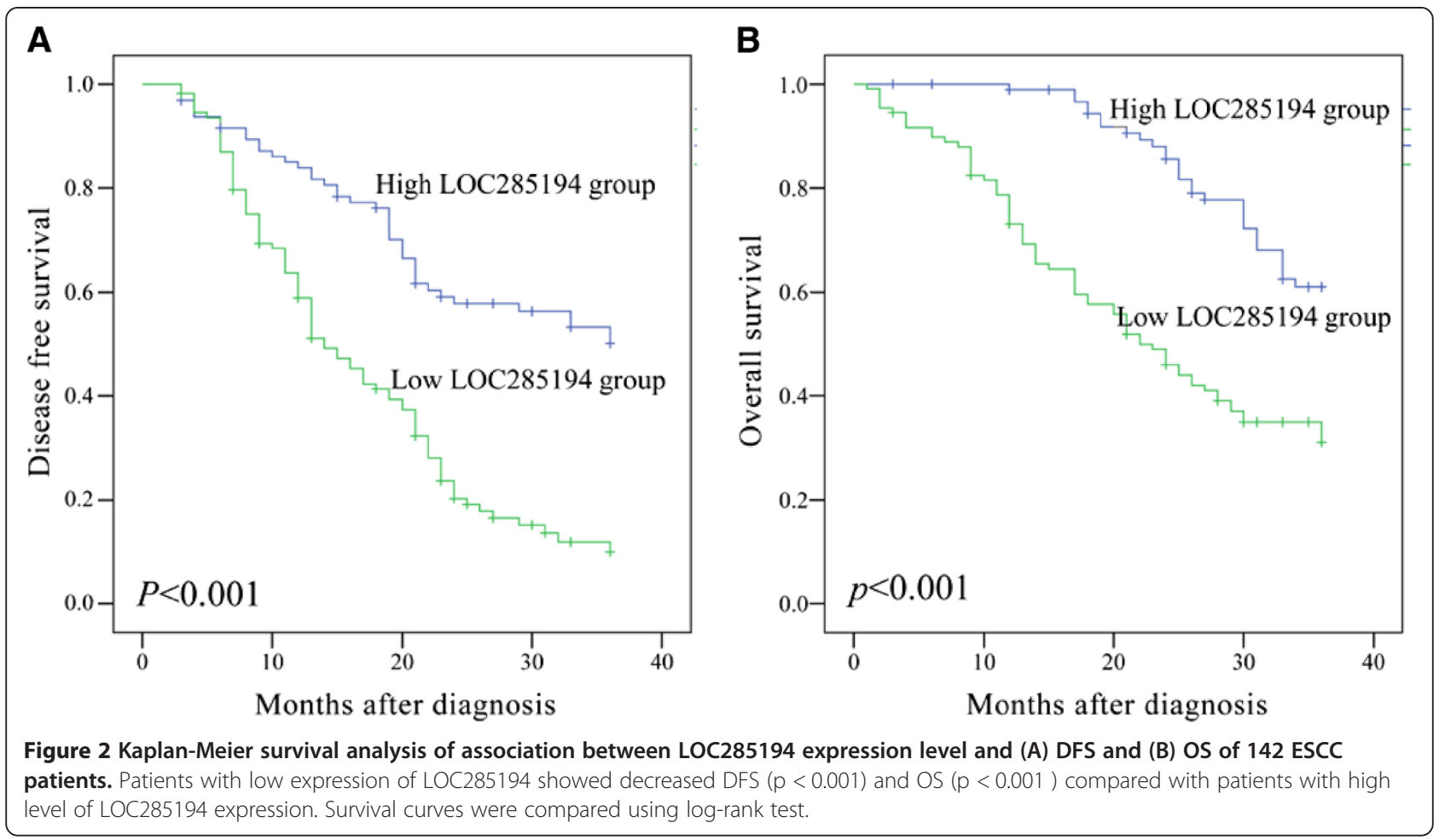

in ESCC patients receiving preoperative CRT. Here, we demonstrated for the first time that low expression of LOC285194 was significantly negatively correlated with pathologic response to CRT. In other words, patients with low expression of LOC285194 suggested resistance to CRT. Indeed, in the CRT $+\mathrm{S}$ group, we found that $57 \%$ $(16 / 28)$ of the LOC285194- high group had a pathCR to CRT compared with only $15 \%(4 / 27)$ in the LOC285194low group. Therefore, our results indicated that low expression of LOC285194 could be a valuable molecular marker for personal treatment screening of ESCC patients before esophagectomy. In addition, rescuing the expression of LOC285194 may have a novel clinical application in the treatment of ESCC patients. However, the exact mechanisms underlying how misexpression of LOC285194 influences the CRT sensitivity have not been fully understood. It has been reported that LOC285194 is located at osteo3q13.31, which harbors frequent focal copy number alterations (CNAs) and loss of heterozygosity $(\mathrm{LOH})$ in osteosarcoma. And depletion of LOC285194 promotes osteoblast proliferation in vitro through regulation of cell cycle transcripts such as cyclin D1 and VEGF/ VEGFR1 [14]. Interestingly, focal osteo3q13.31 depletion and $\mathrm{LOH}$ are also found in various tumors including esophageal cancer [26]. In addition, previous reports have shown that up-regulation of cyclin D1, VEGF and VEGFR1

Table 3 Multivariate cox regression analysis of independent predicting factors for disease free survival and overall survival

\begin{tabular}{|c|c|c|c|c|c|c|}
\hline \multirow[b]{2}{*}{ Factors } & \multicolumn{3}{|c|}{ Disease free survival } & \multicolumn{3}{|c|}{ Overall survival } \\
\hline & $\mathrm{HR}$ & $95 \% \mathrm{Cl}$ & $P$ value & HR & $95 \% \mathrm{Cl}$ & $P$ value \\
\hline Tumor size $(>5: \leq 5)$ & 1.137 & $0.650-1.991$ & 0.653 & 1.030 & $0.564-1.880$ & 0.924 \\
\hline WHO grade $(\mathrm{G} 3, \mathrm{G} 4 / \mathrm{G} 1, \mathrm{G} 2)$ & 1.019 & $0.607-1.981$ & 0.760 & 1.046 & $0.553-1.979$ & 0.889 \\
\hline T status $(\mathrm{T} 3 / \mathrm{T} 31, \mathrm{~T} 2)$ & 1.503 & $0.675-3.347$ & 0.318 & 0.773 & $0.299-1.997$ & 0.594 \\
\hline N status (positive/negative) & 1.360 & $0.539-3.431$ & 0.514 & 1.360 & $0.467-3.996$ & 0.573 \\
\hline M status (M1-lym/M0) & 2.123 & $1.063-4.240$ & $0.033^{*}$ & 2.389 & $1.132-5.041$ & $0.022^{*}$ \\
\hline Clinical stage (III/I + II) & 1.179 & $0.427-3.256$ & 0.750 & 2.408 & $0.735-7.882$ & 0.146 \\
\hline LOC285194 (low/high) & 0.341 & $0.193-0.602$ & $0.001^{*}$ & 0.388 & $0.210-0.715$ & $0.002^{*}$ \\
\hline
\end{tabular}

$\mathrm{HR}$, hazard ratio; $\mathrm{Cl}$, confidence interval; $\mathrm{M} 1-\mathrm{lym}$, distant lymph node metastasis; ${ }^{*} P<0.05$ 
are associated with CRT resistance and poor prognosis in ESCC patients $[27,28]$. Thus, we hypothesize that changes LOC285194 might be involved in the regulation of the expression of proliferation-associated genes that in turn may partly contribute to tumor resistance in preoperative CRT. Clearly, further cell experiments are needed to fully understand the oncogenic function of LOC285194 in human ESCC pathogenesis, including the elucidation of which signaling pathways are involved in resistance to CRT.

One of the most important findings in the present study was the prognostic significance of LOC285194 expression in ESCC. We observed a close association between low expression of LOC285194 and shorter DFS and OS in patients with ESCC. Furthermore, the multivariate analysis showed that low expression of LOC285194 was a powerful independent prognosis factor of poor DFS and OS, which was consistent with the previous reports in colorectal cancer and osteosarcoma. These findings suggested that low expression of LOC285194 could signify a higher risk of disease recurrence and/or treatment failure, and, that postoperative ESCC patients should be closely monitored and receive effective adjuvant therapies.

\section{Conclusion}

Our study shown that LOC285194 expression was significantly down-regulated in ESCC tumor tissues and cell lines, and low expression of LOC285194 was associated with CRT resistance and poor prognosis. Furthermore, decreased expression of LOC285194 could potentially serve as a molecular marker to predict the clinical outcomes (shorter DFS and OS) of ESCC patients after surgery, and select patients who will benefit from the preoperative CRT.

\section{Competing interests}

The authors declared that they have no competing interests.

\section{Authors' contribution}

YT, XZ, BZ and XC Conceived and designed the experiments and were responsible for data analysis and writing the manuscript. QW, XW, JY and JL were responsible for providing the clinical samples. TY and HX were responsible for performing the experiments and data collection. All authors read and approved the final manuscript.

\section{Authors' information}

Yu-suo Tong and Xi-lei Zhou contributed equally to this work and should be considered as joint first authors.

\section{Acknowledgements}

This work was supported in part by National Nature Science Foundation of China (Grant No. H1617/81201881).

\section{Author details}

'Department of Surgical Oncology, Affiliated Nanjing Hospital of Nanjing Medical University and Oncology Center of Nanjing Medical University, Nanjing, Jiangsu, China. ${ }^{2}$ Department of Medical Oncology, Affiliated Nanjing Hospital of Nanjing Medical University and Oncology Center of Nanjing Medical University, Nanjing, Jiangsu, China. ${ }^{3}$ Department of Radiation Oncology, Affiliated Huai'an First Hospital of Nanjing Medical University, Huai'an, Jiangsu, China. ${ }^{4}$ Department of Thoracic Surgery, Affiliated Huai'an First Hospital of Nanjing Medical University, Huai'an, Jiangsu, China.
${ }^{5}$ Department of Medical Oncology, Affiliated Huai'an First Hospital of Nanjing Medical University, Huai'an, Jiangsu, China.

Received: 30 March 2014 Accepted: 18 August 2014

Published: 29 August 2014

\section{References}

1. Jemal A, Bray F, Center MM, Ferlay J, Ward E, Forman D: Global cancer statistics. CA Cancer J Clin 2011, 61:69-90.

2. Sarbia M, Ott N, Pühringer-Oppermann F, Brücher BL: The predictive value of molecular markers ( $\mathrm{p} 53, \mathrm{EGFR}$, ATM, CHK2) in multimodally treated squamous cell carcinoma of the oesophagus. Br J Cancer 2007, 97:1404-1408.

3. Izzo JG, Malhotra U, Wu TT, Ensor J, Luthra R, Lee JH, Swisher SG, Liao Z, Chao KS, Hittelman WN, Aggarwal BB, Ajani JA: Association of activated transcription factor nuclear factor $B$ with chemoradiation resistance and poor outcome in esophageal carcinoma. J Clin Oncol 2006, 24:748-754.

4. van Hagen P1, Hulshof MC, van Lanschot JJ, Steyerberg EW, van Berge Henegouwen MI, Wijnhoven BP, Richel DJ, Nieuwenhuijzen GA, Hospers GA, Bonenkamp JJ, Cuesta MA, Blaisse RJ, Busch OR, ten Kate FJ, Creemers GJ, Punt CJ, Plukker JT, Verheul HM, Spillenaar Bilgen EJ, van Dekken $H$, van der Sangen MJ, Rozema T, Biermann K, Beukema JC, Piet AH, van Rij CM, Reinders JG, Tilanus HW, van der Gaast A, CROSS Group: Preoperative chemoradiotherapy for esophageal or junctional cancer. N Engl J Med 2012, 366:2074-2084.

5. Berger AC1, Farma J, Scott WJ, Freedman G, Weiner L, Cheng JD, Wang H, Goldberg M: Complete response to neoadjuvant chemoradiotherapy in esophageal carcinoma is associated with significantly improved survival. J Clin Oncol 2005, 23:4330-4337.

6. Rohatgi P1, Swisher SG, Correa AM, Wu TT, Liao Z, Komaki R, Walsh GL, Vaporciyan AA, Rice DC, Roth JA, Ajani JA: Characterization of pathologic complete response after preoperative chemoradiotherapy in carcinoma of the esophagus and outcome after pathologic complete response. Cancer 2005, 104:2365-2372.

7. Qi P, Du X: The long non-coding RNAs, a new cancer diagnostic and therapeutic gold mine. Mod Pathol 2013, 26:155-165.

8. $\mathrm{Li} \mathrm{CH}$, Chen Y: Targeting long non-coding RNAs in cancers: Progress and prospects. Int J Biochem Cell Biol 2013, 45:1895-1910.

9. Chen FJ1, Sun M, Li SQ, Wu QQ, Ji L, Liu ZL, Zhou GZ, Cao G, Jin L, Xie HW, Wang CM, LV J, De W, Wu M, Cao XF: Upregulation of the long noncoding rna hotair promotes esophageal squamous cell carcinoma metastasis and poor prognosis. Mol Carcinog 2013, 52:908-915.

10. Gupta RA1, Shah N, Wang KC, Kim J, Horlings HM, Wong DJ, Tsai MC, Hung T, Argani P, Rinn JL, Wang Y, Brzoska P, Kong B, Li R, West RB, van de Vijver MJ, Sukumar S, Chang HY: Long non-coding RNA HOTAIR reprograms chromatin state to promote cancer metastasis. Nature 2010, 464:1071-1076.

11. Gutschner T1, Hämmerle M, Eissmann M, Hsu J, Kim Y, Hung G, Revenko A, Arun G, Stentrup M, Gross M, Zörnig M, MacLeod AR, Spector DL, Diederichs S: The noncoding RNA MALAT1 is a critical regulator of the metastasis phenotype of lung cancer cells. Cancer Res 2013, 73:1180-1189.

12. Panzitt K, Tschernatsch MM, Guelly C, Moustafa T, Stradner M, Strohmaier HM, Buck CR, Denk H, Schroeder R, Trauner M, Zatloukal K: Characterization of HULC, a novel gene with striking Up-regulation in hepatocellular carcinoma, as noncoding RNA. Gastroenterology 2007, 132:330-342.

13. Spizzo R, Almeida MI, Colombatti A, Calin GA: Long non-coding RNAs and cancer: a new frontier of translational research? Oncogene 2012, 31:4577-4587.

14. Pasic 11, Shlien A, Durbin AD, Stavropoulos DJ, Baskin B, Ray PN, Novokmet A, Malkin D: Recurrent focal copy-number changes and loss of heterozygosity implicate Two noncoding RNAs and One tumor suppressor gene at chromosome 3q13.31 in osteosarcoma. Cancer Res 2010, 70:160-171.

15. Liu Q1, Huang J, Zhou N, Zhang Z, Zhang A, Lu Z, Wu F, Mo YY: LncRNA loc285194 is a p53-regulated tumor suppressor. Nucleic Acids Res 2013, 41:4976-4987.

16. Qi P, Xu MD, Ni SJ, Huang D, Wei P, Tan C, Zhou XY, Du X: Low expression of LOC285194 is associated with poor prognosis in colorectal cancer. J Trans/ Med 2013, 11:122.

17. Chirieac LR1, Swisher SG, Ajani JA, Komaki RR, Correa AM, Morris JS, Roth JA, Rashid A, Hamilton SR, Wu TT: Posttherapy pathologic stage predicts 
survival in patients with esophageal carcinoma receiving preoperative chemoradiation. Cancer 2005, 103:1347-1355.

18. He LRT, Liu MZ, Li BK, Jia WH, Zhang Y, Liao YJ, Chen YC, Zhang LJ, Guan $X Y$, Zeng YX, Kung HF, Xie D: High expression of EZH2 is associated with tumor aggressiveness and poor prognosis in patients with esophageal squamous cell carcinoma treated with definitive chemoradiotherapy. Int J Cancer 2010, 127:138-147.

19. Wapinski O, Chang HY: Long noncoding RNAs and human disease. Trends Cell Biol 2011, 21:354-361.

20. Asuthkar S1, Velpula KK, Chetty C, Gorantla B, Rao JS: Epigenetic regulation of miRNA-211 by MMP-9 governs glioma cell apoptosis, chemosensitivity and radiosensitivity. Oncol Target 2012, 3:1439-1454.

21. Gao H1, Wang LD, Zhou Q, Hong JY, Huang TY, Yang CS: p53 tumor suppressor gene mutation in early esophageal precancerous lesions and carcinoma among high-risk populations in Henan, China. Cancer Res 1994, 54:4342-4346.

22. Abedi-Ardekani B1, Kamangar F, Sotoudeh M, Villar S, Islami F, Aghcheli K, Nasrollahzadeh D, Taghavi N, Dawsey SM, Abnet CC, Hewitt SM, Fahimi S, Saidi F, Brennan P, Boffetta P, Malekzadeh R: Extremely high Tp53 mutation load in esophageal squamous cell carcinoma in Golestan Province, Iran. PLoS One 2011, 6:e29488.

23. Ito T1, Kaneko K, Makino R, Ito H, Konishi K, Kurahashi T, Kitahara T, Mitamura K: Prognostic value of $\mathrm{p} 53$ mutations in patients with locally advanced esophageal carcinoma treated with definitivechemoradiotherapy. J Gastroenterol 2001, 36:303-311.

24. Akutsu Y, Hanari N, Yusup G, Komatsu-Akimoto A, Ikeda N, Mori M, Yoneyama Y, Endo S, Miyazawa Y, Matsubara H: COX2 expression predicts resistance to chemoradiotherapy in esophageal squamous cell carcinoma. Ann Surg Oncol 2011, 18:2946-2951.

25. Courrech Staal EF1, Aleman BM, Boot $H$, van Velthuysen ML, van Tinteren $H$, van Sandick JW: Systematic review of the benefits and risks of neoadjuvant chemoradiation for oesophageal cancer. Br J Surg 2010, 97:1482-1496.

26. Forbes SA1, Bhamra G, Bamford S, Dawson E, Kok C, Clements J, Menzies A, Teague JW, Futreal PA, Stratton MR: The Catalogue of Somatic Mutations in Cancer (COSMIC). Curr Proloc Hum Genet 2008, Chater 10:unit 10.11.

27. Shimada H1, Takeda A, Nabeya Y, Okazumi Sl, Matsubara H, Funami Y, Hayashi H, Gunji Y, Kobayashi S, Suzuki T, Ochiai T: Clinical significance of serum vascular endothelial growth factor in esophageal squamous cell carcinoma. Cancer 2001, 92:663-669.

28. Brücher BL1, Keller G, Werner M, Müller U, Lassmann S, Cabras AD, Fend F, Busch R, Stein H, Allescher HD, Molls M, Siewert JR, Höfler H, Specht K: Using Q-RT-PCR to measure cyclin D1, TS, TP, DPD, and Her-2/neu as predictors for response, survival, and recurrence in patients with esophageal squamous cell carcinoma following radiochemotherapy. Int J Colorectal Dis 2008, 24:69-77.

doi:10.1186/s12967-014-0233-y

Cite this article as: Tong et al:: Association of decreased expression of long non-coding RNA LOC285194 with chemoradiotherapy resistance and poor prognosis in esophageal squamous cell carcinoma. Journal of Translational Medicine 2014 12:233.

\section{Submit your next manuscript to BioMed Central and take full advantage of:}

- Convenient online submission

- Thorough peer review

- No space constraints or color figure charges

- Immediate publication on acceptance

- Inclusion in PubMed, CAS, Scopus and Google Scholar

- Research which is freely available for redistribution

Submit your manuscript at www.biomedcentral.com/submit
C Biomed Central 